\title{
Investigation of Silver Nanostructures and Their Influence on the Fluorescence Spectrum of Erbium-Doped Glasses ${ }^{*}$
}

\author{
Victor O. Obadina, B. Rami Reddy ${ }^{\#}$ \\ Department of Physics, Alabama A\&M University, Normal, USA \\ Email: " rami.bommareddi@aamu.edu
}

Received November 26, 2012; revised December 27, 2012; accepted January 4, 2013

\begin{abstract}
Sodium borate glasses embedded with silver were made by the melt quenching technique. Glass transition temperature was recorded by thermal analysis of the sample. As made glasses revealed emission in the visible region under nitrogen laser and excimer laser excitations. Heat treatment was used to induce silver metallic particles. Absorption spectra revealed a peak at $417 \mathrm{~nm}$ due to surface Plasmon resonance. Particle size was estimated to be $2.6 \pm 0.2 \mathrm{~nm}$. Erbium and silver co-doped multielement oxide glasses were made by the melt quenching technique followed by heat treatment to induce nanoparticles. In heat treated samples, $\mathrm{Er}^{3+}$ luminescence increased $4 \times$ due to enhanced field in the vicinity of silver particles. Under excimer laser excitation, $\mathrm{Er}^{3+}$ and $2 \% \mathrm{Ag}$ co-doped glass revealed $\mathrm{Er}^{3+}$ transitions due to enhanced field at the rare-earth ions. Under $795 \mathrm{~nm}$ laser excitation $\mathrm{Er}^{3+}$ green upconversion signals are found to be $4 \times$ stronger in $2 \% \mathrm{Ag}$ co-doped, heat treated sample, than the others.
\end{abstract}

Keywords: Silver Nanoparticles; Field Enhanced $\mathrm{Er}^{3+}$ Luminescence; $\mathrm{Ag} ; \mathrm{Er}^{3+} \mathrm{Co}-$ Doped Oxide Glass; Sodium Borate Glass

\section{Introduction}

Glasses are easy to make and at the same time they can be tailored to specific applications. Rare-earth ion doped glasses have wide ranging applications because of their use as luminescent devices and lasers [1]. The vibrational frequencies of glasses [2] are high when compared to those of halide crystals [3]. As a result quantum yield is low in glasses for some of the fluorescing levels because, the nonradiative relaxation rate is high. To overcome this problem there was some interest to make oxyfluoride glasses which facilitate the crystallization of fluorides by heat treatment [4]. Alternately the rare-earth ion luminescence also increases if the electric field intensity increases at the location of the rare-earth ion [5] or if there is efficient energy transfer to the luminescent centers [6]. For this purpose there have been some efforts to make metal and rare-earth ion co-doped glasses [7,8]. Metals like silver, gold and copper grow as nanoparticles upon heat treatment due to reduction [9]. Surface Plasmon resonance is induced in these metal particles at optical frequencies [9] which in turn were known to enhance rare-earth luminescence [10]. Though there are several efforts in this direction the mechanisms responsible for luminescence enhancement are not fully understood.

\footnotetext{
${ }^{*}$ This research was supported by NSF grant HRD 0927644.

${ }^{\#}$ Corresponding author.
}

Here we have synthesized silver doped sodium borate glasses and investigated surface Plasmon resonance studies in them. We also made metal and rare-earth ion codoped glasses and investigated their luminescence characteristics. Our results are summarized here. This work is carried out because these investigations help in the design of highly efficient luminescent materials.

\section{Experimental}

Sodium borate glass was made with the following composition: $\mathrm{Na}_{2} \mathrm{CO}_{3}(33 \mathrm{~mol} \%), \mathrm{B}_{2} \mathrm{O}_{3}(65 \mathrm{~mol} \%)$ and $\mathrm{AgO}$ ( $2 \mathrm{~mol} \%)$. Appropriate quantities of the chemicals were mixed thoroughly and then melted in a box furnace using alumina crucible, in ambient air at $1400^{\circ} \mathrm{C}$ for 50 minutes. At high temperatures sodium carbonate decomposes into sodium oxide. The resulting melt was poured into an alumina mold and allowed the melt to cool to room temperature naturally. The resulting glass was polished on all sides for the spectral recordings. Using similar procedure we made a few other glasses whose composition and melting temperatures are shown in Table 1. All the samples were annealed at $200^{\circ} \mathrm{C}$ for an hour. Thermal analysis of the glass was performed using NETZSCH model DSC 404 C Pegasus ${ }^{\circledR}$ differential scanning calorimeter (DSC). Sample absorption spectrum was recorded using a Cary 3E spectrophotometer. Fluorescence was gener- 
Table 1. Sample composition of different glasses.

\begin{tabular}{|c|c|c|c|}
\hline $\mathrm{s} / \mathrm{n}$ & Glass chemical composition (mol\%) & $\mathrm{MT}\left({ }^{\circ} \mathrm{C}\right)$ & HT \\
\hline 1 & $\mathrm{Na}_{2} \mathrm{O}(33 \%), \mathrm{B}_{2} \mathrm{O}_{3}(65 \%), \mathrm{AgO}(2 \%)$ & 1400 & Yes \\
\hline 2 & $\mathrm{Na}_{2} \mathrm{O}(31 \%), \mathrm{B}_{2} \mathrm{O}_{3}(63 \%), \mathrm{AgO}(6 \%)$ & 1400 & Yes \\
\hline 3 & $\begin{array}{c}\mathrm{Na}_{2} \mathrm{O}(10 \%), \mathrm{B}_{2} \mathrm{O}_{3}(10 \%), \mathrm{TeO}_{2}(33 \%), \\
\mathrm{GeO}_{2}(33 \%), \mathrm{La}_{2} \mathrm{O}_{3}(10 \%), \operatorname{AgO}(2 \%), \\
\mathrm{ErF}_{3}(2 \%)\end{array}$ & 1150 & Yes \\
\hline 4 & $\begin{array}{c}\mathrm{Na}_{2} \mathrm{O}(10 \%), \mathrm{B}_{2} \mathrm{O}_{3}(10 \%), \mathrm{TeO}_{2}(25 \%), \\
\mathrm{GeO}_{2}(33 \%), \mathrm{La}_{2} \mathrm{O}_{3}(19 \%), \mathrm{AgO}(1 \%) \\
\mathrm{ErF}_{3}(2 \%)\end{array}$ & 1175 & Yes \\
\hline 5 & $\begin{array}{c}\mathrm{Na}_{2} \mathrm{O}(10 \%), \mathrm{B}_{2} \mathrm{O}_{3}(10 \%), \mathrm{TeO}_{2}(25 \%), \\
\mathrm{GeO}_{2}(33 \%), \mathrm{La}_{2} \mathrm{O}_{3}(19 \%), \mathrm{AgO}(1 \%) \\
\mathrm{ErF}_{3}(2 \%)\end{array}$ & 1175 & No \\
\hline
\end{tabular}

s/n: sample number; MT: melting temperature; HT: heat treated.

ated by exciting the sample with Argon ion, Nitrogen, Excimer or Ti: Sapphire lasers. The emitted light was collected by a fiber whose other end was attached to the entrance slit of a medium resolution monochromator. The photomultiplier tube (PMT) output was acquired by a computer for further processing. For lifetime measurement the PMT output was acquired by a Stanford research systems multichannel scaler (SR430). Lifetimes were derived by fitting the decay signals to single exponentials. An optical microscope was used to image larger particles.

\section{Results and Discussion}

The glass has to be heat treated to induce metallic particles. So, one has to know the approximate temperature range for heat treatment. Glass transition temperature is defined for amorphous materials. Above this temperature the material is in the rubber-like state and dopant ions migrate to form nanocrystals. For this purpose glass transition temperature was measured using a differential scanning calorimeter under nitrogen atmosphere at a constant heating rate $10^{\circ} \mathrm{C} / \mathrm{min}$ (Figure 1). It is clear from Figure 1 that the glass transition temperature is $467^{\circ} \mathrm{C}$. Absorption spectrum of the as made glass did not reveal any distinct peak in the visible region, but the absorption increased gradually at shorter wavelengths. All these glass samples did not reveal emission under any $\mathrm{Ar}^{+}$laser excitation. However, when the samples were excited with a $337.1 \mathrm{~nm} \mathrm{~N} \mathrm{~N}_{2}$ laser, it revealed three broad peaks in the visible region centered at 450,500 and $560 \mathrm{~nm}$. These peaks overlapped at higher silver concentrations (Figure 2). The measured lifetimes of 450, 500 and $560 \mathrm{~nm}$ signals are $39.2,57.3$ and $34 \mu$ s respectively. One such decay curve is shown in Figure 3. The decay time was obtained by fitting a single exponential function to the decay signal (fitting is not shown). The long lifetimes of these peaks indicate that these peaks are not due to surface Plasmon (SP) because the emission wavelengths are

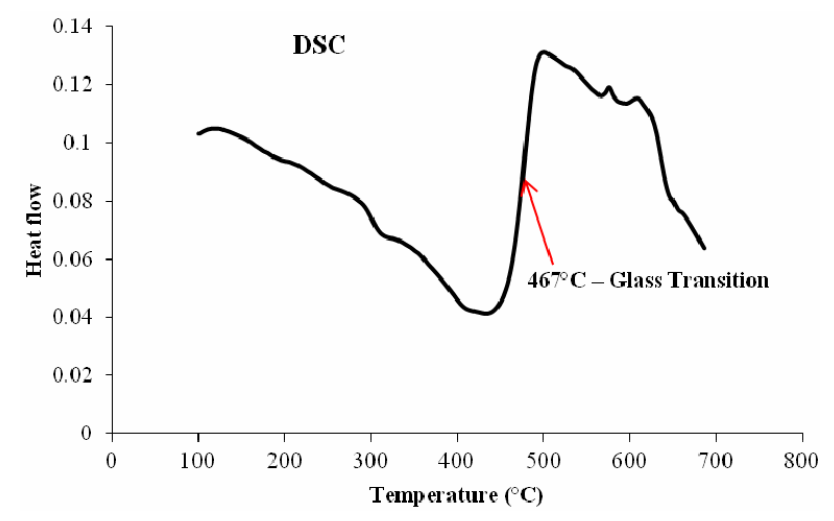

Figure 1. DSC of Ag doped sodium borate glass showing the glass transition temperature at $467^{\circ} \mathrm{C}$.

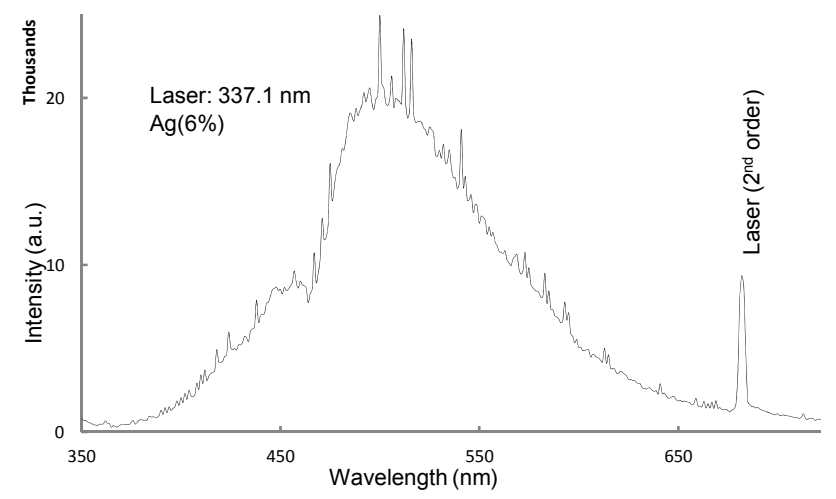

Figure 2. Fluorescence spectrum of silver doped Sodium borate glass observed under $337.1 \mathrm{~nm} \mathrm{~N}_{2}$ laser excitation. The peaks centered at 450,500 , and $560 \mathrm{~nm}$ overlapped.

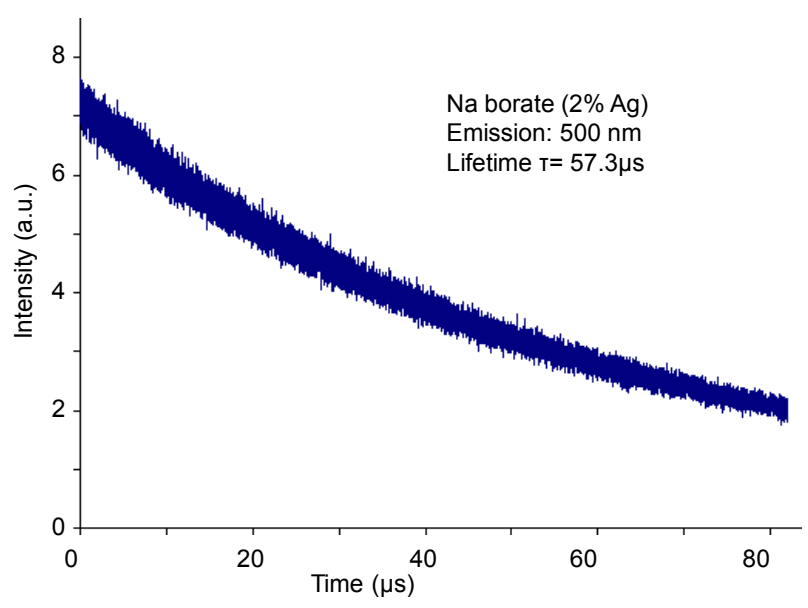

Figure 3. Temporal evolution of $450 \mathrm{~nm}$ emission observed under $337.1 \mathrm{~nm}$ laser excitation.

longer and the measured lifetimes are much longer than those expected for Plasmon relaxation times. The emission is due to molecular aggregates of silver $[10,11]$. Under $308 \mathrm{~nm}$ laser (excimer) excitation, sodium borate doped with Ag (2\%) exhibited emission at 355, 510 and $700 \mathrm{~nm}$ (Figure 4). However in a $\mathrm{Ag}(6 \%)$ doped sodium 


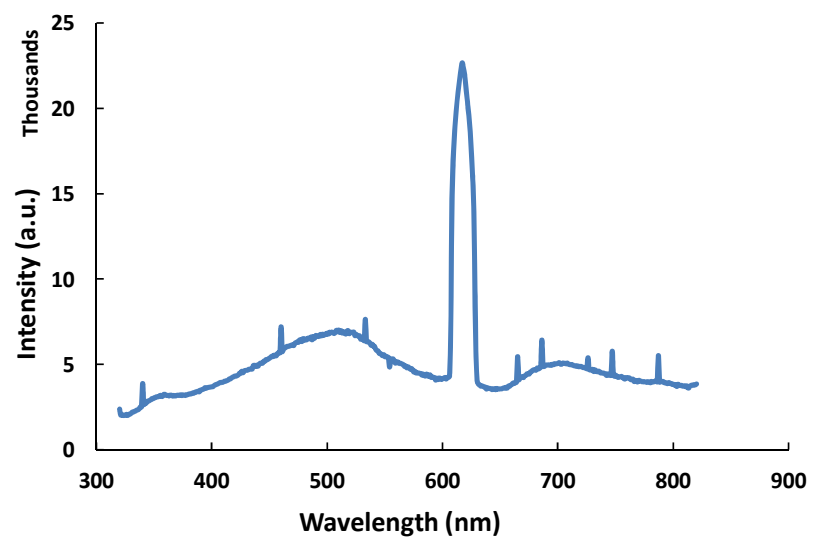

Figure 4. Emission observed from sodium borate glass embedded with Ag (2 mol\%) under $308 \mathrm{~nm}$ excimer laser excitation.

borate the peaks are shifted to 355,480 and $840 \mathrm{~nm}$ and the $480 \mathrm{~nm}$ peak intensity is much higher than that of 840 $\mathrm{nm}$ (not shown). The measured lifetimes of the emission peaks at 355, 510 and $700 \mathrm{~nm}$ are respectively 48, 180 and $95 \mu \mathrm{s}$. The difference in lifetimes suggest that the fluorescing levels are different from those excited by the nitrogen laser.

One of our objectives is to induce metallic nanoparticles in the glass. So the glass was subjected to several heat treatments successively and we monitored its absorption spectrum after each treatment (Figure 5). Curves (a) and (b) were recorded before and after heat treatment at $470^{\circ} \mathrm{C}$ for $8 \mathrm{~h}$. Heat treatment increased the overall absorption in the visible region. Upon heat treatment at $500^{\circ} \mathrm{C}$ for $17 \mathrm{~h}$, the sample revealed a small absorption peak at $417 \mathrm{~nm}$ (curve (c)). The absorption at $417 \mathrm{~nm}$ is due to surface plasmon resonance (SPR) $[13,14]$. After heat treating the same sample at $520^{\circ} \mathrm{C}$ for $6 \mathrm{~h}$, its absorption peak intensity increased (curve (d)). This suggests that the particle concentration has increased. On the other hand, when the same sample was heat treated for $12 \mathrm{~h}$ at $520^{\circ} \mathrm{C}$ the absorption peak wavelength shifted to $380 \mathrm{~nm}$, suggesting that the particle size has decreased. When the spectrum of the as made glass was subtracted from that of the heat treated glass it revealed a prominent peak at $417 \mathrm{~nm}$ (Figure 6). This peak confirms the existence of Ag nanoparticles in the glass. At plasma resonance local field enhances by a large value, which in turn contributes to fluorescence enhancement of the dopant ions. From a measurement of its full-width at half maximum (FWHM), $50 \mathrm{~nm}$, the metallic particle size was estimated $[5,13]$ as $2.6 \pm 0.2 \mathrm{~nm}$, by using $2 \mathrm{R}=\mathrm{v}_{\mathrm{f}} / \Delta \omega_{1 / 2}$, where the Fermi velocity, $\mathrm{v}_{\mathrm{f}}=1.39 \times 10^{6} \mathrm{~m} / \mathrm{s}$. Figure 6 also reveals couple of small peaks in the $500-600 \mathrm{~nm}$ region which fall in the region of silver exciton spectrum [15]. An optical microscope image of the sample revealed the presence of micron size Ag particles (Figure 7)

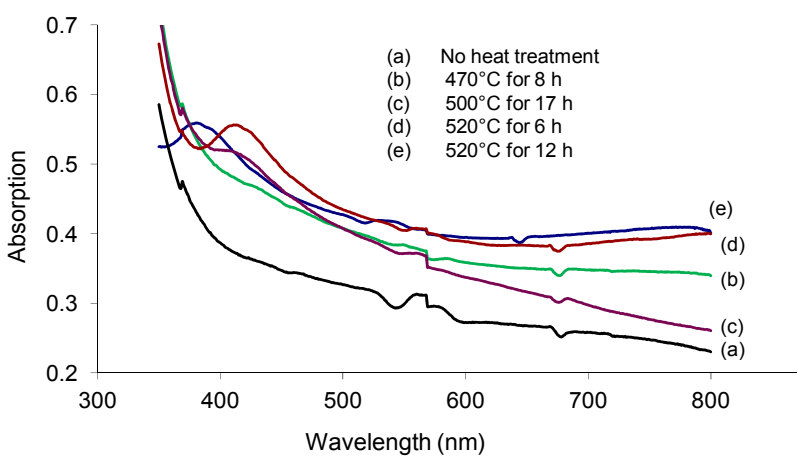

Figure 5. Absorption spectrum of Ag doped sodium borate glass observed before and after heat treatment at different temperatures and time durations.

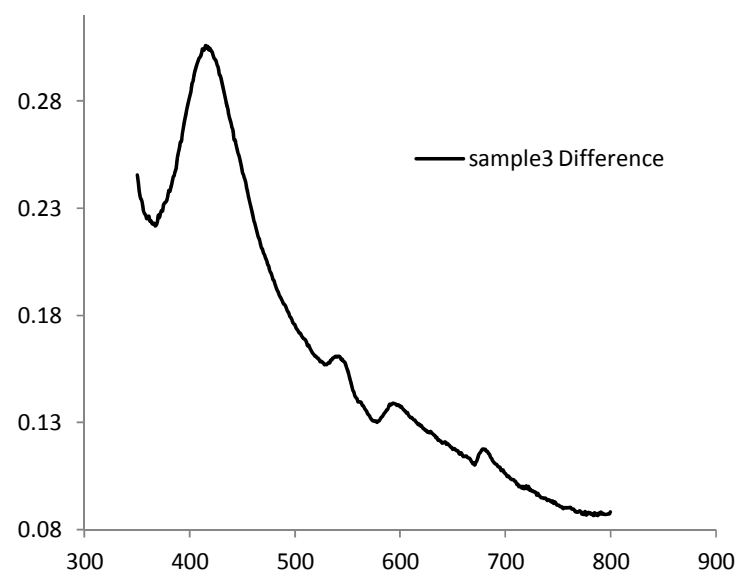

Figure 6. Absorption spectrum of surface plasmon resonance.

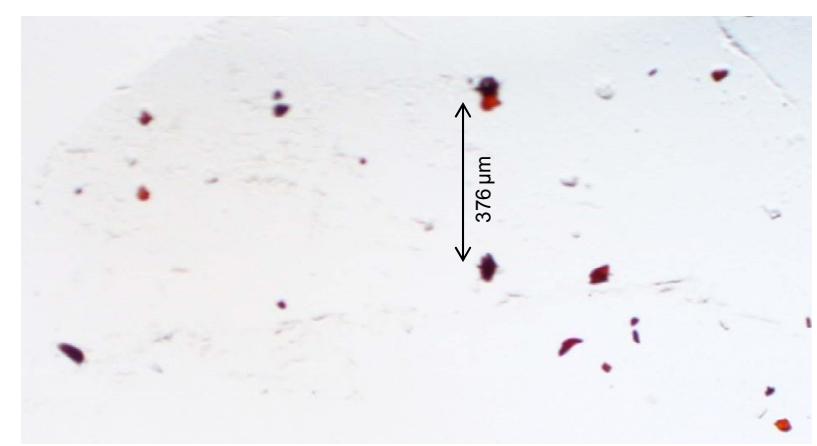

Figure 7. Optical microscope image of a heat treated glass reveals micron size particles.

in it, in addition to nanoparticles.

We were interested in studying the effect of silver particles, if any, on the luminescence of rare-earth ions. Because the vibrational frequency of borates is very large [2] rare-earths do not exhibit high emission intensities in them. So we modified the glass composition as shown in Table 1 for samples 3-5. The glasses contain $2 \mathrm{~mol} \%$ $\mathrm{Er}^{3+}$ as co-dopant in addition to silver. For samples 3 to 5 shown in Table 1, the $\mathrm{Er}^{3+}$ concentration is $2 \mathrm{~mol} \%$ but 
the silver concentration is different, $1 \mathrm{~mol} \%$ or $2 \mathrm{~mol} \%$. Absorption spectrum revealed all the $\mathrm{Er}^{3+}$ peaks as expected (Figure 8). The ground state of $\mathrm{Er}^{3+}$ is ${ }^{4} \mathrm{I}_{15 / 2}$ and the excited states are identified on the same figure. A partial energy level diagram is constructed using the absorption spectrum (Figure 9). The $488 \mathrm{~nm}$ laser resonantly excites the ${ }^{4} \mathrm{~F}_{7 / 2}$ level of $\mathrm{Er}^{3+}$. The excited ions relax nonradiatively to ${ }^{4} \mathrm{~S}_{3 / 2}$ level causing the latter to emit green fluorescence in the range $500-600 \mathrm{~nm}\left({ }^{4} \mathrm{~S}_{3 / 2}\right.$, ${ }^{2} \mathrm{H}_{11 / 2} \rightarrow{ }^{4} \mathrm{I}_{15 / 2}$ ). Figure 10 compares the emission spectra of two samples. Both the samples have the same $\mathrm{Er}^{3+}$ concentration ( $2 \mathrm{~mol} \%$ ); but different $\mathrm{Ag}$ concentrations ( $1 \mathrm{~mol} \%$ and $2 \mathrm{~mol} \%$ ). Optical microscope image revealed that the $2 \% \mathrm{Ag}$-doped sample has higher concentration of $\mathrm{Ag}$ metallic particles. The $\mathrm{Er}^{3+}$ fluorescence intensity in $2 \% \mathrm{Ag}$ co-doped sample is $4 \times$ higher than that of $1 \mathrm{~mol} \% \mathrm{Ag}$ doped sample. When we recorded the emission on the short wavelength side of the laser another interesting effect occurred. $\mathrm{Er}^{3+}$ and $\mathrm{Ag}(2 \%)$ codoped sample revealed emission at $415 \mathrm{~nm}$ that was absent or too weak in 1\% Ag doped sample (Figure 11). This indicates that $\mathrm{Ag}$ particles are playing a role on $\mathrm{Er}^{3+}$ emission intensity. To further understand the effect of $\mathrm{Ag}$ particles we measured the lifetime of $\mathrm{Er}^{3+}$ fluorescence in all the glasses. The lifetime of ${ }^{4} \mathrm{~S}_{3 / 2}$ level is $10 \mu \mathrm{s}$ in all the glasses. This implies that we do not have any evidence that supports energy transfer from $\mathrm{Ag}$ aggregates (molecular form) to $\mathrm{Er}^{3+}$. This also suggests that the enhancement in $\mathrm{Er}^{3+}$ luminescence is due to field enhancement caused by nearby Ag metallic particles [7]. Probably $488 \mathrm{~nm}$ laser weakly excites SPR in Ag particles, which in turn enhance field at the nearby $\mathrm{Er}^{3+}$ ion sites. Under $308 \mathrm{~nm}$ excitation, sample 5 (not heat treated) revealed three broad emission peaks centered at 355,510 and $700 \mathrm{~nm}$, whose positions and shapes are same as that of $2 \%$ Ag-doped (sample 1) sodium borate glass (see Figure 4). On the other hand, the heat treated and codoped glass (sample 3) revealed $\mathrm{Er}^{3+}$ peaks at 390, 480, 510, 540, 790 and $820 \mathrm{~nm}$ (Figure 12). Obviously this indicates that $\mathrm{Ag}$ particles influenced emission intensities of $\mathrm{Er}^{3+}$ transitions.

Accordingly, 2\% Ag doped sample revealed abundant metallic particles, after heat treatment. So, in this sample a relatively large number of $\mathrm{Er}^{3+}$ ions are in the vicinity of $\mathrm{Ag}$ metallic particles. Surprisingly, in a $2 \mathrm{~mol} \% \mathrm{Ag}$ sample an intense peak appeared at $420 \mathrm{~nm}$ (not shown) and no such peak occurred in $1 \mathrm{~mol} \% \mathrm{Ag}$ sample. This sample was heat treated at $370^{\circ} \mathrm{C}$ for an hour. Optical microscope images revealed crystallites, whose sizes extend up to several microns. When the samples were excited with $795 \mathrm{~nm}$ laser green emission occurred from ${ }^{4} \mathrm{~S}_{3 / 2},{ }^{2} \mathrm{H}_{11 / 2}$ levels $\left({ }^{4} \mathrm{~S}_{3 / 2},{ }^{2} \mathrm{H}_{11 / 2} \rightarrow{ }^{4} \mathrm{I}_{15 / 2}\right)$, as shown in Figure 13. Upconversion occurs due to stepwise two-photon excitation. One such scheme is shown in Figure 9. All

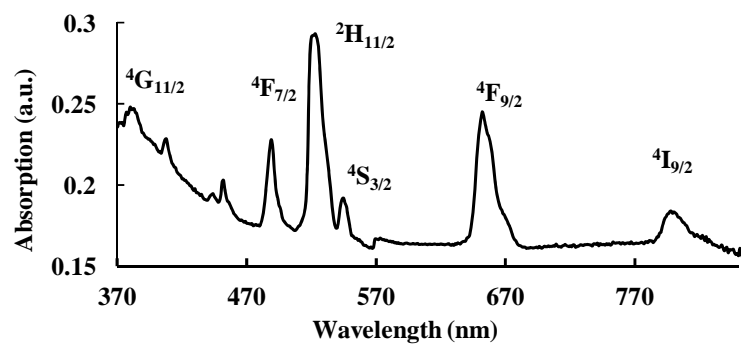

Figure 8. Absorption spectrum of $\mathrm{Er}^{3+}$ doped glass.

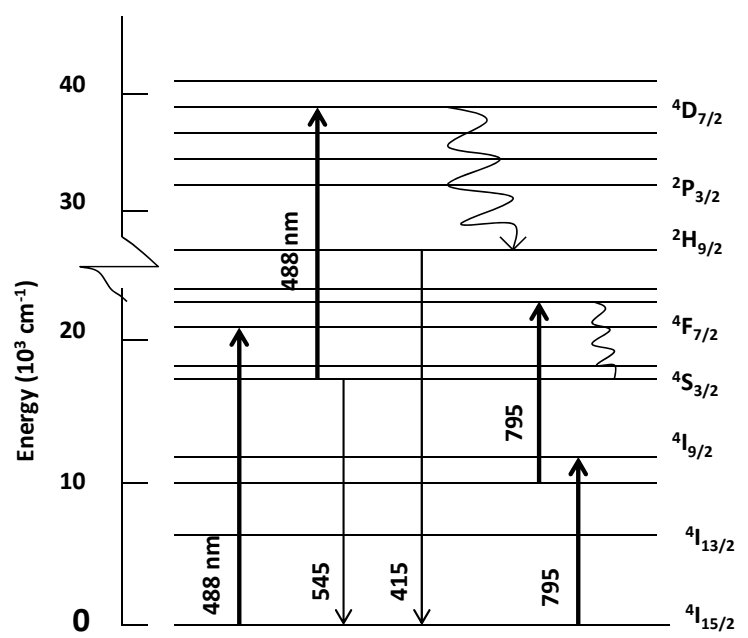

Figure 9. Partial energy level diagram of $\mathrm{Er}^{3+}$-doped glass. Upward and downward arrows represent absorption and emission transitions. Wavy arrows represent nonradiative transitions.

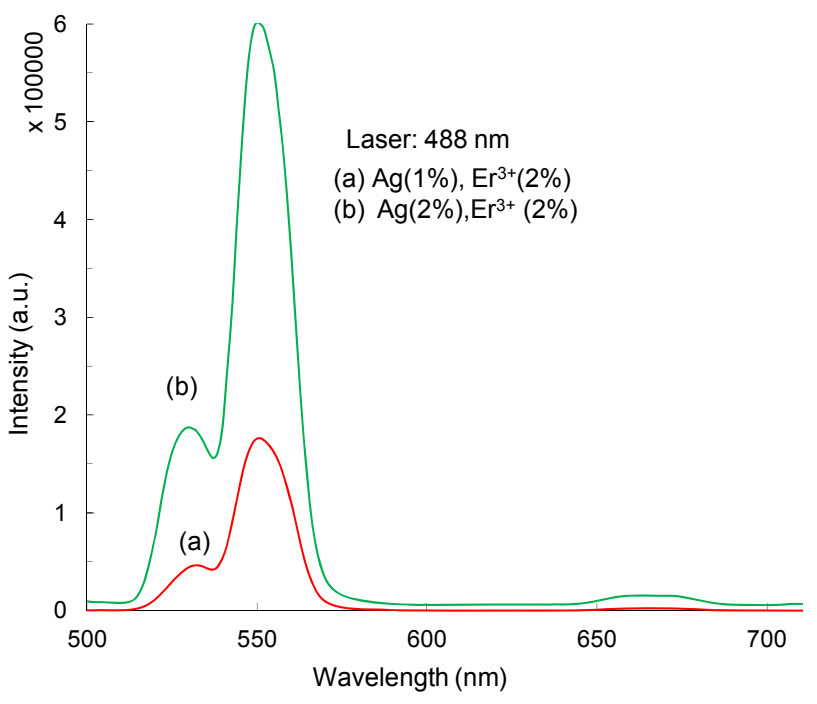

Figure 10. Fluorescence spectrum $\left({ }^{4} S_{3 / 2},{ }^{2} \mathbf{H}_{11 / 2} \rightarrow{ }^{4} I_{15 / 2}\right)$ observed under $488 \mathrm{~nm}$ laser excitation from samples 3 and 4 .

the samples contain $2 \% \mathrm{Er}^{3+}$ but different $\mathrm{Ag}$ concentrations. These observations suggest that the increased emission may be due to enhanced field in the vicinity of $\mathrm{Ag}$ nanoparticles. 


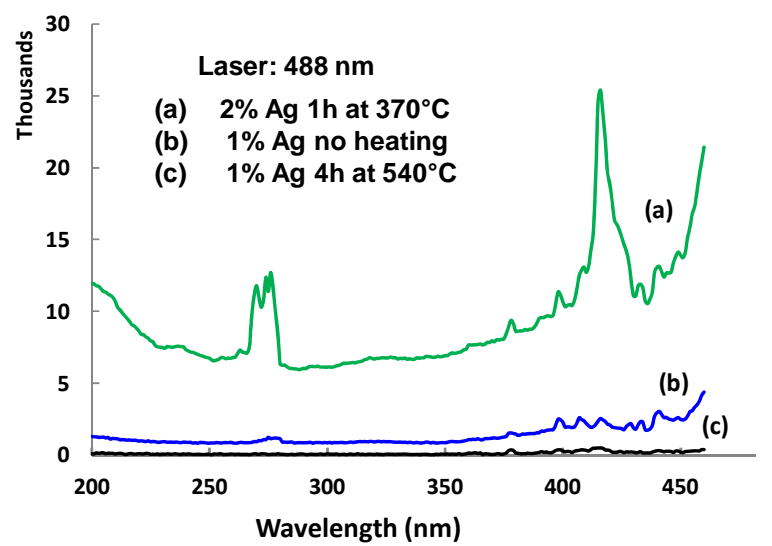

Figure 11. Emission spectrum observed from samples 3-5 under $488 \mathrm{~nm}$ laser excitation.

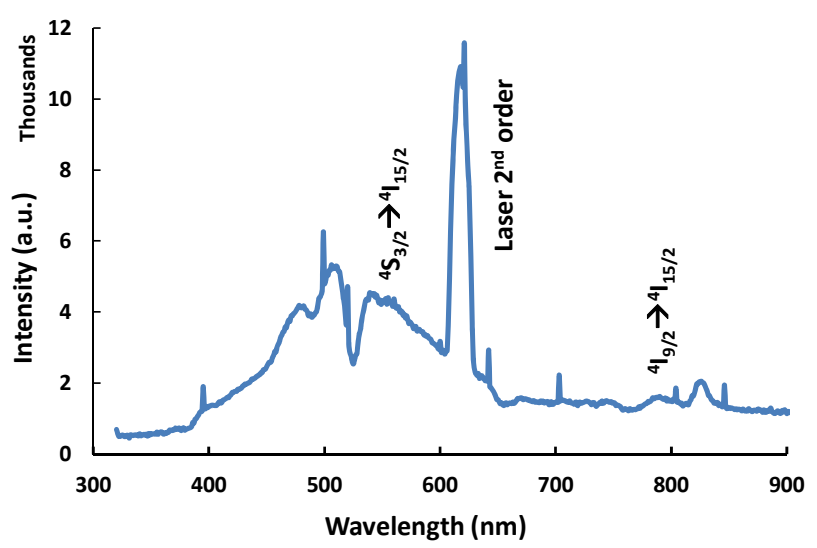

Figure 12. fluorescence spectrum observed from sample 3 under $308 \mathrm{~nm}$ laser excitation.

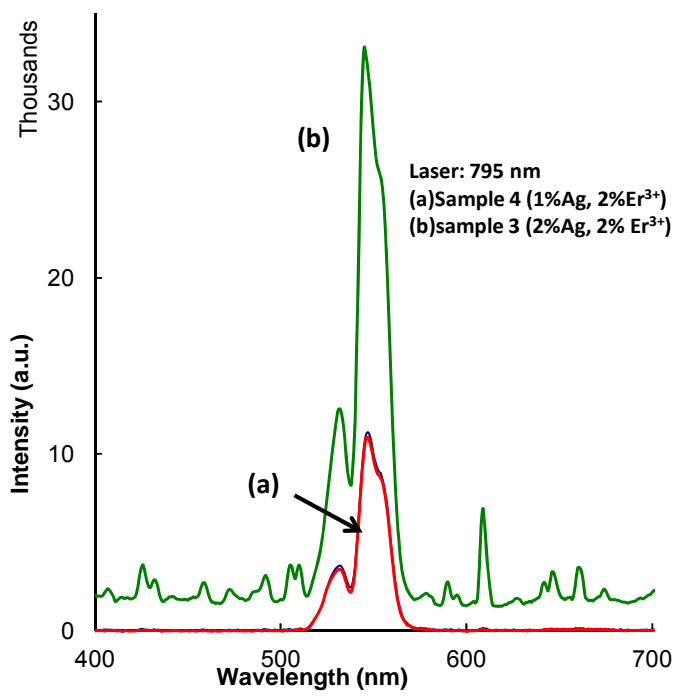

Figure 13. Energy upconversion spectrum $\left({ }^{4} \mathbf{S}_{3 / 2},{ }^{2} \mathbf{H}_{11 / 2} \rightarrow{ }^{4} \mathbf{I}_{15 / 2}\right)$ observed under $795 \mathrm{~nm}$ laser excitation.

\section{Conclusion}

Sodium borate glasses embedded with silver were made by the melt quenching technique. Glass transition temperature was found to be $467^{\circ} \mathrm{C}$ by thermal analysis of the sample. As made glasses revealed emission in the visible region under nitrogen laser and excimer laser excitations, due to the formation of $\mathrm{Ag}$ aggregates (molecular form). Heat treatment was used to induce silver metallic particles. Absorption spectra revealed a peak at $417 \mathrm{~nm}$ due to surface Plasmon resonance. Particle size was estimated to be $2.6 \mathrm{~nm}$. Erbium and silver co-doped multielement oxide glasses were made by the melt quenching technique followed by heat treatment to induce $\mathrm{Ag}$ nanoparticles. In heat treated samples $\mathrm{Er}^{3+}$ luminescence increased $4 \times$ due to field enhancement in the vicinity of silver particles.

\section{REFERENCES}

[1] B. R. Reddy, "Stepwise Two-Photon Excitation Studies in Fibers and Crystals for Energy Upconversion and Infrared Quantum Counter Devices," Proceedings of SPIE, Vol. 2000, 2000, pp. 87-114.

[2] C. B. Layne, W. H. Lowdermilk and M. J. Weber, "Multiphonon Relaxation of Rare-Earth Ions in Oxide Glasses," Physical Review B, Vol. 16, No. 1, 1977, pp. 10-20. doi:10.1103/PhysRevB.16.10

[3] L. A. Riseberg and H. W. Moose, "Multiphonon Orbit Relaxation of Excited States of Rare-Earth Ions in Crystals," Physical Review, Vol. 174, No. 2, 1968, pp. 429438. doi:10.1103/PhysRev.174.429

[4] M. Dejneka, "Rare-Earth Luminescence in Novel Oxyfluoride Glasses and Glass Ceramics," Proceedings of SPIE, Vol. 3280, 1998, pp. 132-139. doi:10.1117/12.305402

[5] T. Hayakawa, S. T. Selvan and M. Nogami, "Field Enhancement Effect of Small Ag Particles on the Fluorescence from $\mathrm{Eu}^{3+}$-Doped $\mathrm{SiO}_{2}$ Glass," Applied Physics Letters, Vol. 74, No. 11, 1999, pp. 1513-1515. doi:10.1063/1.123600

[6] C. Strohhofer and A. Polman, "Silver as a Sensitizer for Erbium," Applied Physics Letters, Vol. 81, No. 8, 2002, pp. 1414-1416. doi:10.1063/1.1499509

[7] L. P. Naranjo, C. B. D. Araujo, O. L. Malta, P. A. Santa Cruz and L. R. P. Kassab, "Enhancement of $\operatorname{Pr}^{3+}$ Luminescence in $\mathrm{PbO}-\mathrm{GeO}_{2}$ Glasses Containing Silver Nanoparticles," Applied Physics Letters, Vol. 87, No. 24, 2005, pp. 241914-241916. doi:10.1063/1.2143135

[8] L. R. P. Kassab, C. B. D. Araujo, R. A. Kobayashi, R. D. Pinto and D. M. Silva, "Influence of Silver Nanoparticles in the Luminescence Efficiency of $\mathrm{Pr}^{3+}$-Doped Tellurite Glasses," Journal of Applied Physics, Vol. 102, No. 10, 2007, pp. 103515. doi:10.1063/1.2817980

[9] B. J. Messinger, K. U. von Raben, R. K. Chang and P. W. Barber, "Local Fields at the Surface of Noble-Metal Microsphere," Physical Review B, Vol. 24, No. 2, 1981, pp. 649-657. doi:10.1103/PhysRevB.24.649

[10] V. O. Obadina and B. R. Reddy, "Effect of Silver Nanoparticles on the Spectral Properties of Rare-Earth Ions in 
a Sodium Borate Glass," Proceedings of SPIE, Vol. 8271, 2012, Article ID: 827104. doi:10.1117/12.905458

[11] C. Sonnichsen, T. Franzl, T. Wilk, G. von Plessen and J. Feldmann, "Plasmon Resonances in Large Noble-Metal Clusters," New Journal of Physics, Vol. 4, 2002, pp. 93.1-93.8.

[12] H. Guo, X. Wang, J. Chen, and F. Li, "Ultrviolet Light Induced White Light Emission in $\mathrm{Ag}$ and $\mathrm{Eu}^{3+} \mathrm{Co}-\mathrm{Doped}$ Oxyfluoride Glasses," Optics Express, Vol. 18, No. 18, 2010, pp. 18900-18905. doi:10.1364/OE.18.018900

[13] S. Lee, et al., "Spectral Change in Silver-Doped SodiumBorate Glass by Using Femtosecond Laser Irradiation,"
Journal of Korean Physical Society, Vol. 52, 2008, pp. 1665-1668. doi:10.3938/jkps.52.1665

[14] J. A. Jimenez, S. Lysenko, G. Zhang and H. Liu, "Optical Properties of Silver-Doped Aluminophosphate Glasses," Journal of Material Science, Vol. 42, No. 5, 2007, pp. 1856-1863. doi:10.1007/s10853-006-0898-6

[15] P. Gangopadyaya, R. Kesavamoorthy, S. Bera, P. Magudapathy, K. G. M. Nair, B. K. Panigrahi and S. V. Narasimhan, "Optical Absorption and Photoluminescence Spectroscopy of the Growth of Silver Nanoparticles," Physical Review Letters, Vol. 94, No. 4, 2005, Article ID: 047403. doi:10.1103/PhysRevLett.94.047403 